References:

[1] Lupus 2011; 20:125-130.

[2] Clin Rheumatol 2014; 33:1209-1215.

Disclosure of Interest: None declared

DOI: 10.1136/annrheumdis-2017-eular.5733

\section{FRI0274 MORFOLOGICAL INDEXES IN LUPUS NEPHRITIS - DO THEY HAVE PROGNOSTIC VALUE?}

D. Navarro, A.C. Ferreira, H. Viana, F. Carvalho, F. Nolasco. Nephrology Department, Hospital Curry Cabral, Lisboa, Portugal

Background: Lupus nephritis (LN) is a serious complication of systemic lupus erythematosus (SLE). With current therapies, a high remission rate is observed, this being the most important prognostic factor. Currently, therapy is guided by findings in the renal biopsy, following the ISN/RPS classification. Although recommended by EULAR, Austin and Hill's morphological indexes are not routinely obtained.

Objectives: To analyze the importance and applicability of the different morphological indexes in predicting response to treatment and prognosis.

Methods: Retrospective single center study of consecutive SLE and biopsy proven LN patients, diagnosed from 2010 to 2016. We evaluated the following outcomes: clinical remission, renal function and proteinuria at end of follow-up (FUP) $(\mathrm{g} / 24 \mathrm{~h})$. Complete remission was defined as a reduction of proteinuria to $<0,5 \mathrm{~g} / 24 \mathrm{~h}$, inactive urinary sediment and serum creatinine $<115 \%$ of baseline; partial remission same parameters, except proteinuria $<1 \mathrm{~g} / 24 \mathrm{~h}$ if initial value $<3 \mathrm{~h} / 24 \mathrm{~h}$, or reduction to $<3 \mathrm{~g} / 24 \mathrm{~h}$ if initial value $>3 \mathrm{~g} / 24 \mathrm{~h}$. The studied predictors were the INS/RPS LN classification and the morphological indexes described by Austin (Activity and Chronicity) and Hill, obtained after histomorphological review of renal biopsies. Statistical analysis was performed with STATA software.

Results: During 6 years, there were 46 biopsy-proven LN cases, 84,8\% ( $n=39)$ woman, median 35 years old $(27-42,5)$ and $57,6 \%(n=19)$ caucasian. 39 patients were already known to have SLE, 7,44 $(1,13-12,3)$ years previously.

The median FUP was $31,9(13,2-45,6)$ months. Based on biopsy findings, 35 patients were started on immunosuppression - induction in $50 \%$ of cases with MMF and in $50 \%$ with cyclophosphamide; maintenance in $81 \%$ with MMF, the remaining with azathioprine. Complete remission was achieved in $58 \%$ of patients, $27 \%$ achieving partial remission. We observed $4 \mathrm{LN}$ relapses. $96 \%(n=44)$ of the patients survived at the end of FUP, with a median serum creatinine of $0,8 \mathrm{mg} / \mathrm{dl}$ $(0,7-0,99)$, eGFR $99,8 \mathrm{ml} / \mathrm{min}(71,2-116,8)$ and proteinuria of $0,6 \mathrm{~g} / 24 \mathrm{~h}(0,2-$ $1,6)$.

We observed that Class IV patients had, at presentation, lower eGFR (67,3 vs $94,6 \mathrm{ml} / \mathrm{min} ; \mathrm{p}=0,02)$, higher proteinuria $(4,26 \mathrm{vs} 2,37 ; p=0,02)$ and a tendency towards higher C3 consumption (58,9 vs 77,$4 ; p=0,06)$. We did not observe correlations between ISN/RNP Classification and the outcomes at the end of FUP. The correlations between clinical findings and morphological indexes (Hill and Austin) are summarized in table 1:

Table 1

\begin{tabular}{|c|c|c|c|c|c|c|}
\hline & \multicolumn{2}{|c|}{$\begin{array}{l}\text { Hill Biopsy } \\
\text { Index }\end{array}$} & \multicolumn{2}{|c|}{$\begin{array}{l}\text { Activity } \\
\text { Index }\end{array}$} & \multicolumn{2}{|c|}{$\begin{array}{l}\text { Chronicity } \\
\text { Index }\end{array}$} \\
\hline & $\mathrm{R}$ & $p$ & $\mathrm{R}$ & $p$ & $R$ & $p$ \\
\hline Anti-dsDNA (IU/ml) & 0,2 & NS & 0,3 & 0,005 & $-0,07$ & NS \\
\hline C3 $(\mathrm{mg} / \mathrm{dl})$ & $-0,2$ & NS & $-0,3$ & 0,003 & 0,1 & NS \\
\hline $\mathrm{C} 4(\mathrm{mg} / \mathrm{dl})$ & $-0,2$ & NS & $-0,3$ & 0,004 & 0,1 & NS \\
\hline Presentation serum creatinine $(\mathrm{mg} / \mathrm{dl})$ & 0,3 & 0,03 & 0,1 & NS & 0,3 & 0,03 \\
\hline Presentation eGFR (ml/min) & $-0,5$ & 0,01 & $-0,3$ & NS & $-0,4$ & 0,004 \\
\hline Presentation proteinuria (g/24h) & 0,6 & 0,001 & 0,4 & 0,009 & $-0,3$ & 0,006 \\
\hline End of FUP serum creatinine $(\mathrm{mg} / \mathrm{dl})$ & 0,3 & 0,046 & 0,07 & NS & $-0,4$ & 0,002 \\
\hline End of FUP eGFR $(\mathrm{ml} / \mathrm{min})$ & $-0,2$ & NS & 0,09 & NS & $-0,5$ & 0,002 \\
\hline End of FUP proteinuria ( $\mathrm{g} / 24 \mathrm{~h}$ ) & 0,4 & 0,02 & 0,2 & NS & 0,3 & 0,003 \\
\hline
\end{tabular}

Both the Hill biopsy index and the Chronicity index were correlated with renal function and proteinuria at the end of FUP. The Activity index correlated with the immunological findings - C3, C4 and anti-dsDNA.

Conclusions: EULAR guidelines suggest that histomorphological evaluation in LN should go beyond ISN/RNP classification, and our data supports that - we observed a correlation between the renal outcomes and the indexes described by Austin and Hill.

Disclosure of Interest: None declared

DOI: 10.1136/annrheumdis-2017-eular.3816

\section{FRI0275 SYSTEMIC LUPUS ERYTHEMATOSUS PATIENTS WITH POSITIVES AUTOANTIBODIES WITH REMISSION OR LOW ACTIVITY EXHIBIT BOTH LOWER INTERFERON ALPHA AND INTERLEUKIN-10 LEVELS}

E. Grau Garcia ${ }^{1}$, F.M. Ortiz-Sanjuan ${ }^{1}$, M. Fernandez Matilla ${ }^{2}$, C.M. Feced Olmos $^{1}$, E. Labrador Sánchez ${ }^{1}$, N. Fernández-Llanio ${ }^{2}$, I. Chalmeta Verdejo ${ }^{1}$, K. Arévalo Ruales ${ }^{1}$, R. Negueroles Albuixech ${ }^{1}$, J. Ivorra Cortes ${ }^{1}$, J.J. Fragio Gil $^{1}$, I. Martínez Cordellat ${ }^{1}$, R. González Mazarío ${ }^{1}$, L. Gonzalez Puig ${ }^{1}$, C. Alcañiz Escandell ${ }^{1}$, C. Nájera Herranz ${ }^{1}$, I. Cánovas Olmos ${ }^{1}$, E. Vicens Bernabeu $^{1}$, J.E. Oller Rodriguez ${ }^{1}$, J.A. Castellano Cuesta ${ }^{2}$, V. Fornés Ferrer ${ }^{3}$,
D. Hervás Marín ${ }^{3}$, J.A. Román Ivorra ${ }^{1} .{ }^{1}$ Rheumatology Department, HUP la Fe; ${ }^{2}$ Rheumatology Section, Hospital Arnau de Vilanova; ${ }^{3}$ Biostatistics Unit, IIS la Fe, Valencia, Spain

Background: Systemic lupus erythematous (SLE) is an autoimmune disease characterized by immune system disruption, including $\mathrm{T}$ and $\mathrm{B}$ cell activation and upregulation of autoantibody and immunocomplexes production that could damage different organs. Sometimes, patients with positives autoantibodies and serological manifestations show low disease activity or clinical remission. There is not enough information about persistent positive autoantibodies in absence of clinical activity neither the role of proinflamatory cytokines in this context.

Objectives: To assess the clinical and molecular differences in SLE patients with positives autoantibodies and with low clinical activity or in clinical remission compared to the group with clinical activity.

Methods: A cross-sectional, observational study of patients diagnosed of SLE according to SLICC 2012 criteria was performed. In these patients a complete blood-test was made, and clinical data by personal interview was collected We analyzed the serum concentration of IL10, BLyS and INF1A by colorimetric methods. Biostatistical analysis was performed with R 3.3.2.

Results: We selected 130 SLE patients with serological manifestations (defined by RELESSER study) out of 142 SLE patients. 91 cases showed low activity or remission $($ SLEDAI $<6$ ) and 39 presented moderate or high activity (SLEDAI $>6$ ). SLE patients with positives autoantibodies without clinical activity showed significantly lower anti-dsDNA levels $(P=0.006)$, lower complement consumption $(P=0.003)$ and lower accumulated damage evaluated by SLICC score $(P=0.041)$. No differences on time of evolution in both groups were observed. In addition, SLE patients with positives autoantibodies without clinical activity exhibit significantly lower levels of IL10 $(P<0.001)$ and INF1A $(P=0.019)$. No differences on BLyS levels in both groups were observed. Finally, SLE patients with positives autoantibodies with clinical activity present more mucocutaneous lesions $(P=0.014)$, musculoskeletal manifestations $(P=0.004)$, neuropsychiatric manifestations $(P=0.002)$, renal manifestations $(P<0.001)$ and lymphopenia $(P=0.008)$ than patients with positives autoantibodies and without clinical activity.

Conclusions: In our series of SLE patients with both serological manifestations and low clinical activity have lower levels of IL10 and INF1A, compared to patients with high clinical activity. This result would suggest that differences in the cytokine levels are not related to autoantibodies presence but there are other mechanisms involved in cytokine production that would also be involved in maintenance of clinical remission.

Disclosure of Interest: None declared

DOI: 10.1136/annrheumdis-2017-eular.5766

\section{FRI0276 PREVALENCE OF DEPRESSION BY BECK II AND IMPORTANCE OF FATIGUE BY FACIT IV QUESTIONNAIRES IN SYSTEMIC LUPUS ERYTHEMATOSUS PATIENTS VS CONTROLS IN A SINGLE CENTER OF ARGENTINA}

E. Avid, A. Braillard-Poccard, M. Garcia Carrasco, N. Perez, G. Nasswetter, D. Dubinsky. Rheumatology Division, Hospital de Clinicas Jose de San Martin, Capital Federal, Argentina

Background: Estimated prevalence of neuropsychiatric symptoms in SLE is among 17 to $71 \%^{1}$. Depressive symptoms are around $54 \%^{1,2}$. Fatigue is frequently referred, predicts high morbidity and may be influenced by lifestyle and individual psychological characteristics ${ }^{1}$

Objectives: To evaluate the prevalence of depressive symptoms and its association with demographics and clinical variables in patients with SLE. To determine the predictive value of FACIT for fatigue in SLE vs controls.

Methods: Observational, retrospective case- control design. Patients $\geq 18$ years old with SLE (ACR 97) were consecutively evaluated in our centre from January to July 2015. We analyzed age, disease duration, clinical manifestations, antibodies profile, SLEDAI ( $\geq 4$ scored as active) and SLICC. We recorded familiar psychiatric diseases, educational and socioeconomic level (Graffar Scale), employment and marital status. Beck II and FACIT (IV version) questionnaires were used for evaluate depression and fatigue respectively. We tested two cut points for fatigue: $<22$ and $<40$ to determine sensitivity/specificity for this tool in SLE patients vs controls ${ }^{3}$. Continues data were compared using t Student and Mann Whitney. Categorical data: chi-square or Fisher's exact test by SPSS version 20.0. To predic fatigue we calculated the area under the curve by Receiver Operating Characteristic $(R O C)$. Statistical significant $=p<0.05$.

Results: 77 SLE and 100 controls, all female. SLE vs control group: Mean of age ys: 34 (19-49)vs 38 (19-60). Prevalence of depression: 52\% (44/77) vs $29 \%(29 / 100)(p<0.05)$. Prevalence of fatigue (FACIT $<40): 42 \%(33 / 77)$ and $36 \%(36 / 100)(p>0.05)$. Mean disease duration (months) 48 (24-114). Socio-demographic characteristics, SLICC/SLEDAI, clinical and serological manifestations were not correlated with major depression $\mathrm{p}>0.05$. FACIT: Median value: 31 (range 22-40) SLE group. FACIT<22 total SLE: $12 / 77(15 \%)$ and FACIT<40: 33/77 (42\%). Cut points FACIT SLE vs controls: $<22: 15 \%(12 / 77)$ vs $1 \%(1 / 100)(p<0.05), 30 \%$ sensitivity $/ 100 \%$ specificity, $100 \%$ PPV and $57 \%$ NPV. AUC FACIT <22: 0.65 (0.65-0.77). FACIT $<40$ in SLE vs controls: $42 \%(33 / 77)$ vs $26 \%(26 / 100)(p<0.05), 69 \%$ sensitivity and $84 \%$ specificity, $82 \%$ PPV and $70 \%$ NPV. AUC FACIT<40: 0.75 (0.64-0.87)

Conclusions: Prevalence of depression was high in our cohort and similar to 